DIPEPTIDE TRANSPORT BX THE SMALL INTESTINE OF FETAL AND NEWBORN BABBITS/A.Rubino,S.Guandalini, S.Auricchio.Dopt. Pediatrics, II School of Mod.e Univ. of Naples, Italy. Optake of dipeptides by the intestinal mucosa of rabbits is mediated by at least one saturable carrier system distinct from those translocating aminoacids. The mucosal inPluxes of $0.5 \mathrm{mH}$ ( $14 \mathrm{C}$-Glycine) Glycylproline(GP) and of $0.5 \mathrm{mM}(3 \mathrm{H})$ Glycine (G) are now studied in vitro in the swall intestine of fetal and newborn rabbits.At 25 days of gestation GP influx (pmol/s wet vt., hr; wean \pm SEY) is $9.7 \pm 1.5$ in jejunum and $13.2 \pm 3.7$ in ileum. In jejunum the influx rate shows a 4-fold increase to reach a plateau which covers the period 1 to 10 days after birth and then declines again to the initial levels within the lat mo. of postnatal life. The largest portion of this perinatal increase precedes birth. The development pattern of GP influx in ileum is similar but the degree of perinatal increase is smaller (about 2-101d). In contrast $G$ influx remains constant through the whole age period under study and is lower than GP influx. The molecular specificity of in influx process for GP has been studied in the proximal jejunum of newborns by testing various aminoacids and peptides as inhibitors: the results indicate that the transport system has no or low affinity for aminoacide but is shared by peptides of various composition.

SUBCELLULAR LOCALIZATION OF ENTEROPEPTIDASE (ENTEROKINASE) IN THE HUMAN SMALL INTESTINAL MUCOSA. J.Schmitz, V. Troesch, R. Schneider and B. Hadorn, Hopital des enfants malades, Paris, France and Gastrointestinal Unit Department of Paediatrics, University of Berne, Switzerland.

Brush border bound disaccharidase activities are reduced in the atrophic mucosa of children with active coeliac disease. Enterokinase which is said to have the same subcellular localization as the disaccharidases is however only slightly reduced in coeliac disease. It was suspected therefore that the subcellular localization of enterokinase was more complex than that of sucrase. The enzyme was found in high concentrations in an almost pure preparation of human brush border membrane. A second localization was also found: a fraction of the mucosal homogenate containing only small amounts of brush border but large amounts of endoplasmic reticulum contained a disproportionately high amount of enterokinase. The enzyme occurred in a particulate and not fully active form. To our knowledge this is the first report of an intracellular localization for an intestinal enzyme. One wonders if this intracellular form represents a precursor of the active brush border bound enterokinase.

COLONIC PERFUSION STUDIES IN CONGENITAL CHLORIDE DIARRHOEA.C.Holmberg, K. Launiala and J.Perheentupa, Children's Hospital. University of Helsinki.SF-00290 Helsinki, Finland. Congenital chloride diarrhoea,an autosomal recessive disease characterized by hydramnios and persistently watery stools with high $\mathrm{Cl}^{-}$concentration has been described in 17 patients outside Finland. We have seen 17 cases of which 14 are still alive and doing vell. The basic defect of this disease has been postulated to be an inability to absorb $\mathrm{Cl}^{-}$in the distal ileum and possibly in the colon. We have studied 3 patients and 3 healthy siblings to determine the presence and nature of the colonic electrolyte transport defect. A double lumen perfusion tube was brought into the proximal colon and fluid was collected $10 \mathrm{~cm}$ from the infusion point and from the anus. Polyethylene glycol was used as a nonabsorbable marker for water movement and $36 \mathrm{Cl}$ to measure influx and outflux of $\mathrm{Cl}^{-}$. Perfusions with a physiological salt solution showed no difference from controls in $\mathrm{Na}^{+}$absorption but with $\mathrm{Na}+$ concentration of $24 \mathrm{mM}$ the CCD-patients showed secretion in contrast to absorption in controls. $\mathrm{K}^{+}$and $\mathrm{H}^{+}$ were secreted at markedly higher rate in CCD.Controls absorbed $\mathrm{Cl}^{-}$from luminal concentration as low as $15 \mathrm{mH}$ whereas CCD-patients absorbed $\mathrm{Cl}^{-}$only in minimal amounts and from luminal concentration of over 70mM. Bicarbonate secretion was probably masked byth secretion in CCD. Deficient $\mathrm{CI}^{-}$absorption is probably the primary defect and increased sedretion of $\mathrm{K}^{+}$and $\mathrm{B}^{+}$is a secondary phenomenon.

\section{VARIOUS TOPICS}

INFLUENCE OF HYPOXIA ON DISTRIBUTION OF CARDIAC OUTPUT AND ORGAN BLOOD FLOW IN THE RABBIT.

Felix Wyler,Children's Hospital,Basel, Switzerland.

Ten spontaneously breathing male New Zealand white rabbits were exposed to a $50 \mathrm{~min}$.period of hypoxia. The arterial p0 averaged $45 \mathrm{mmHg}$.Cardiac output (c.0.) was measured with the dye dilution method, distribution of C.0. and organ blood flow was assessed with left ventricular injection of radioactively labelled microspheres. The results were compared with 8 control animals.

c.0., arterial blood pressure and total peripheral vasc. resistance did not change significantly; distribution of $C .0$. however showed preferential flow to the heart and musculature. The renal flow was markedly reduced; all other organs maintained their blood flow. Cerebral blood flow did not increase because of hypocapnia from slight metabolic acidosis.

The kidney seems to be the target organ from which blood is diverted to other apparently more vital vascular beds. The redistribution of C.0. bears some resemblance to that in low output states.

A NEW APPROACH IN SHOCK THERAPY DURING EARLY LIFE, Experimental study.

G.Hollmann, K.R.Koczorek, T. Angerpointner,H.Hahn, S.Stockel, K.L. Waag, W. Sippell, P. Lehmann and R. Schadwinkel. Kinderchirurgische Klinik der Univ. - Kinderkiinik, Munchen/Germany.

42 puppies (age 14 to 26 days) have been studied in standardized haemorrhagic shock.

During the normovolaemic phase 8 puppies were treated with $1 \mathrm{mg}$ aldosterone $/ \mathrm{kg} / \mathrm{h}, 6$ puppies with $2 \mathrm{mg} / \mathrm{kg} / \mathrm{h}$, over a period of 4 hours. 28 untreated pupies served as controls.

$\mathrm{B} l$ ood pressure, heart rate, rectal temperature, $\mathrm{pH}$ and plasma potassium come back to normal in the aldosterone treated animals. These effects are more evident when $2 \mathrm{mg}$ aldosterone/ $\mathrm{kg} / \mathrm{h}$ are given. Urine production is substantially improved. Average survival time is 1.6 and 6 times longer in animals treated with 1 and $2 \mathrm{mg}$ aldosterone $/ \mathrm{kg} / \mathrm{h}$, respectively, than in controls.

MOTOR NERVE CONDUCTION VELOCITY IN SPINAL MUSCULAR ATROPHY-AN INDEX OF SEVERITY

A. Moosa

Institute of Child Health, Hammersmith Hospital, London.

The conduction velocities of the uinar and posterior tibial nerves were measured in a group of children with spinal muscular atrophy of varying severity. The velocities were found to be reduced in infants with the severe infantile form of the disease (Werdnig-Hoffman type) but were normal in the less severe forms including the benign Kugelberg-Welander type.

The reduction of velocities in the severe form of spinal muscular atrophy is not as great as in demyelinating neuropathies and is probably due to predominant loss of the larger (and therefore faster conducting) nerve fibres. 